\title{
Inspiratory Capacity and Vital Capacity of Healthy Subjects 9-81 Years of Age at Moderate-High Altitude
}

\author{
Silvia Cid-Juárez, Ireri Thirión-Romero, Luis Torre-Bouscoulet, Laura Gochicoa-Rangel, \\ David Martínez-Briseño, Iván Y Hernández-Paniagua, Olivia Delgadillo-Ruiz, \\ Selene Guerrero-Zúñiga, Rodrigo Del Río-Hidalgo, Daniel Cortés-Medina, Peter E Bapo-López, \\ Pablo León-Gómez, Anaid Bautista-Bernal, and Rogelio Pérez-Padilla
}

\begin{abstract}
BACKGROUND: Measurements of inspiratory capacity (IC) and vital capacity (VC) are used to recognize dynamic hyperinflation, but appropriate reference values are required to achieve accurate clinical interpretations. Altitude above sea level is a potential determining factor for lung volumes, including IC and VC. OBJECTIVE: To describe IC and VC for healthy people who live in Mexico City at an altitude of 2,240 $\mathrm{m}$ above sea level. METHODS: Healthy subjects ages 9-81 y completed slow spirometry by following 2005 American Thoracic Society/European Respiratory Society standards. Once associations were explored, linear regression models were constructed and values were compared with those from previously published equations. RESULTS: A total of 441 healthy subjects $(55.1 \%$ women) participated. The mean age was 32 y (minimum age, 9 y; maximum age, 81 y). IC and VC measurements were associated with sex, age, height, and weight. An accelerated increase in IC and VC was evident from 9 to $20 \mathrm{y}$ of age, followed by a gradual decrease in both sexes. In general, IC was higher in our population than predicted by previously published reference equations. CONCLUSIONS: IC in healthy people at $2,240 \mathrm{~m}$ above sea level was higher than that of previous reports about European and Latin-American subjects of the same height, sex, and age who were at sea level. The present study provided robust reference values for persons who lived at a moderate altitude. Key words: inspiratory capacity; reference values; altitude; pulmonary function tests; aging; lung volumes. [Respir Care 2019;64(2):153-160. (C) 2019 Daedalus Enterprises]
\end{abstract}

\section{Introduction}

Inspiratory capacity (IC), which is the volume difference between total lung capacity and the functional resid-

Ms Cid-Juárez, Dr Thirión-Romero, Mr Luis Torre-Bouscoulet, Prof Gochicoa-Rangel, Dr Guerrero-Zúñiga, Dr Río-Hidalgo, Dr CortésMedina, Dr Bapo-López, Dr León-Gómez, Ms Anaid Bautista-Bernal, and Dr Pérez-Padilla are affiliated with the Department of Respiratory Physiology, Instituto Nacional de Enfermedades Respiratorias "Ismael Cosío Villegas," Mexico City, Mexico. Drs Thirión-Romero and Pérez-Padilla are affiliated with the Smoking Cessation and COPD Clinic, Instituto Nacional de Enfermedades Respiratorias "Ismael Cosío Villegas," Mexico City, Mexico. Mr Torre-Bouscoulet is affiliated with the Department of Clinical Investigation, Instituto Nacional de Enfermedades Respiratorias "Ismael Cosío Villegas," Mexico City, Mexico. Mr Martínez-Briseño is affiliated with the Department of Epidemiological and Social Health Science, Instituto Nacional de Enfermedades Respiratorias "Ismael Cosío Villegas," Mexico City, Mexico. Prof Hernández-Paniagua and Ms Olivia Delgadillo-Ruiz are affiliated with Consorcio Centromet, Conacyt, Querétaro, Mexico. ual capacity, has emerged as a physiologic parameter with relevant clinical implications. ${ }^{1,2}$ For instance, a low IC, usually due to air trapping, is predictive for dyspnea, poor quality of life, ${ }^{1-4}$ and low exercise capacity ${ }^{1,5}$ in patients with COPD. In addition, a low IC increases the risk of death in patients with COPD or pulmonary hypertension. ${ }^{6}$

\footnotetext{
Dr Thirión-Romero presented a version of this paper at the European Respiratory Society International Congress held September 9-13 2017, in Milan, Italy.

The authors have disclosed no conflicts of interest.

Correspondence: Rogelio Pérez-Padilla, Instituto Nacional de Enfermedades Respiratorias, Calzada de Tlalpan 4502, Col. Sección XVI, Tlalpan, Ciudad de México (CDMX), México 14080. E-mail: perezpad@gmail.com.
}

DOI: $10.4187 /$ respcare.06284 
According to the American Thoracic Society/European Respiratory Society standards, ${ }^{1,5}$ the ratio of $\mathrm{FEV}_{1}$ to vital capacity (VC), by means of a slow maneuver, ${ }^{7}$ can be used to determine the presence of airway obstruction. ${ }^{8}$ During a slow VC maneuver, less thoracic gas compression occurs and greater air volume can be expired in patients with COPD as the airways collapse during a forced expiration, a mechanism that contributes importantly to exercise impairment. ${ }^{9}$

Although IC and VC are clinically relevant, proper reference values are required to achieve accurate interpretations, but few are available. Besides the typical predictors of lung function, such as height, age, sex, or ethnicity, ${ }^{10,11}$ altitude above sea level is a potential determining factor for lung volumes. ${ }^{12}$ Thus, existing IC and VC reference values may not be applicable to residents of Mexico City who live 2,240 m above sea level. ${ }^{13}$ Our group previously reported higher forced spirometry values for healthy Mexican people than that predicted by reference equations used internationally. ${ }^{13}$ That finding, although incompletely understood, may be due to a larger chest size at altitude. ${ }^{14}$

In this study, we decided to obtain IC and VC by using spirometry rather than plethysmography because both methods provide similar IC values. ${ }^{15}$ When using simple spirometry, the clinician can obtain an easy, fast, low-cost, and reliable IC in his or her office. Thus, the objective of our study was to describe IC and VC by using slow spirometry in a healthy population who live at a moderate altitude. The participants included children and adults under similar measurement conditions (It means that each subject measured height, weight and slow spirometry under similar conditions, in a standardized way) to obtain information on the growth and decline of lung function. We also compared our results with other studies, mostly conducted at sea level, by evaluating IC and VC either directly or indirectly.

\section{Methods}

The study protocol was approved by The National Institute of Respiratory Disease's ethics committee (code C28-13), and the adults or parents of the children who participated in the study signed a letter of informed consent. Testing was conducted from May 2013 to August 2014 at the pulmonary function test laboratory of the National Institute of Respiratory Diseases in Mexico City, a reference center for respiratory diseases where primarily uninsured patients are seen. We included Mexican male and female individuals who resided in the metropolitan area of Mexico City $(2,240 \mathrm{~m}$ above sea level), $>9 \mathrm{y}$ of age, never-smokers $(<400$ cigarettes smoked in their lifetime), non-obese (body mass index [BMI] $<30 \mathrm{~kg} / \mathrm{m}^{2}$ in individuals ages $>18$ y and falling within the $<95$ th percentile of U.S. Center for Disease Control values in younger

\section{QUICK LOOK}

\section{Current knowledge}

Measurements of inspiratory capacity (IC) and vital capacity (VC) are used to recognize dynamic hyperinflation, but published reference values, required to achieve accurate clinical interpretations, are few and utilized either a plethysmographic technique or a slow VC maneuver. In addition, available equations cover a limited range of ages: children or adults. Altitude above sea level is a potential determining factor for lung volumes, including IC and VC.

\section{What this paper contributes to our knowledge}

Our cross-sectional study described the growth and decline of IC and slow VC with similar procedures and equipment by using a widely available spirometric technique. A significant decline with age was observed for IC and was more marked for VC. Healthy residents at moderate altitude (2,240 $\mathrm{m}$ above sea level) had higher values (adjusted by age, height, and sex) than those of previous reports for European and Latin-American subjects studied at sea level.

individuals), without previous respiratory diseases diagnosed by a physician and lacking sustained respiratory symptoms (wheezing, dyspnea, cough, or phlegm). The participants were selected by invitation or through posters, mostly from among National Institute of Respiratory Diseases employees, their relatives, and students (medical, respiratory care, nursing) enrolled in courses at our institution. No participants were active in competitive sports. Ethnic origin is usually not included in surveys applied in Mexico City, and all the participants were considered to be Mexican mestizos.

Spirometry tests and slow VC were performed with pneumotachograph-based equipment (Ergospirometry 5.22.1.149, CareFusion, Baesweiler, Germany) according to American Thoracic Society/European Respiratory Society standards. ${ }^{1,6}$ Volume was verified daily by using a 3-L calibration syringe; maximal acceptable variability was $\pm 3 \%$. Barometric pressure and temperature were automatically taken into account by the equipment. All the tests were performed by experienced trained personnel who possessed spirometry certification by the National Institute of Occupational Safety and Health. We used reference values for spirometry obtained in Mexican-American individuals. ${ }^{16}$

Briefly, the technician explained and demonstrated the maneuver to all the participants. Subsequently, the maneuvers were performed with the subjects seated and wearing a nose clip. Each maneuver consisted of three to ten relaxed respiratory cycles at normal tidal volume to ensure 
Table 1. Characteristics of the Population

\begin{tabular}{|c|c|c|c|}
\hline Characteristic & Total Study Population $(N=441)$ & $\operatorname{Men}[n=199(45 \%)]$ & Women $[n=242(55 \%)]$ \\
\hline Age, median (IQR) y & $32(9-81)$ & $30(9-81)$ & $37(9-81)$ \\
\hline Height, mean $\pm \mathrm{SD} \mathrm{cm}$ & $161.3 \pm 11$ & $168.4 \pm 9.7$ & $155.4 \pm 8.1$ \\
\hline Weight, mean \pm SD kg & $65.5 \pm 14.1$ & $72.3 \pm 14.3$ & $59.9 \pm 11.2$ \\
\hline BMI, mean $\pm \mathrm{kg} / \mathrm{m}^{2}$ & $25.1 \pm 4.2$ & $25.4 \pm 3.9$ & $24.8 \pm 4.4$ \\
\hline BSA, mean $\pm m^{2}$ & $1.7 \pm 0.2$ & $1.8 \pm 0.2$ & $1.6 \pm 0.2$ \\
\hline $\mathrm{FEV}_{1} / \mathrm{FVC}$, mean $\pm \%$ & $82.7 \pm 5$ & $82.0 \pm 5$ & $83.2 \pm 5$ \\
\hline $\mathrm{FEV}_{1}$, mean $\pm \mathrm{L}$ & $3.26 \pm 0.91$ & $3.89 \pm 0.80$ & $2.73 \pm 0.60$ \\
\hline $\mathrm{FEV}_{1}$, mean $\pm \%$ predicted $*$ & $103 \pm 13$ & $103 \pm 12$ & $103 \pm 13$ \\
\hline $\mathrm{FVC}$, mean $\pm \mathrm{L}$ & $3.94 \pm 1.10$ & $4.75 \pm 0.95$ & $3.28 \pm 0.68$ \\
\hline $\mathrm{FVC}$, mean $\pm \%$ predicted $*$ & $103 \pm 12$ & $103 \pm 12$ & $103 \pm 13$ \\
\hline $\mathrm{VC}$, mean $\pm \mathrm{L}$ & $4.00 \pm 1.09$ & $4.84 \pm 0.91$ & $3.31 \pm 0.67$ \\
\hline $\mathrm{IC}$, mean $\pm \mathrm{L}$ & $3.08 \pm 0.82$ & $3.66 \pm 0.75$ & $2.59 \pm 0.50$ \\
\hline $\begin{array}{l}\text { * Percent predicted was calculated by } \\
\mathrm{IQR}=\text { interquartile range } \\
\mathrm{BMI}=\text { body mass index } \\
\mathrm{BSA}=\text { body surface area } \\
\mathrm{VC}=\text { vital capacity } \\
\mathrm{IC}=\text { inspiratory capacity }\end{array}$ & Third National Health and Nutrition Examinatior & nce values. ${ }^{16}$ & \\
\hline
\end{tabular}

stable end-expiratory lung volume. At the end of a normal expiration, the subjects were asked to perform a rapid, maximal inspiration (in $<1 \mathrm{~s}$ ) to reach total lung capacity (the IC maneuver). Next, they were instructed to perform a slow, prolonged expiration until they reached a plateau of at least $1 \mathrm{~s}$ with no increase in volume on the volume-time curve (the VC maneuver). For study purposes, we required a minimum of 3 acceptable maneuvers, with a difference between the 2 highest measures of $<0.150 \mathrm{~L}$. The highest value of the 3 acceptable VC maneuvers and the average of at least 3 IC maneuvers obtained were reported. ${ }^{1,4,6}$ Our intra-test coefficient of variation for IC as well as for VC was $3 \pm 2 \%$.

\section{Statistical Analysis}

We planned to study 300 individuals ages $\geq 9 \mathrm{y}$, half were females. Descriptive statistics were used to characterize the study population. IC and slow VC were modeled by multiple linear regression. Age and anthropometric variables (height, weight, BMI) were used to generate predictive equations by selecting those with biologic plausibility, higher coefficients of determination $\left(\mathrm{R}^{2}\right)$, and lower standard error of estimation separately for males and females. Body surface area was estimated according to Haycock: $0.024265 \times$ height $^{0.3964} \times$ weight $^{0.5378}$. Reference equations were generated for the 50th and 5 th percentiles to indicate the average and the lower limit of normal, respectively. Finally, we compared the participant's measured IC and VC expressed as the percent of predicted by using our reference equation with the same IC and VC values expressed as the percent of predicted of previously published equations ${ }^{3,17-23}$ when using paired $t$ tests. Obtaining subject values that average $>100 \%$ predicted by a published equation would imply that the source population had an IC or VC on average lower than our studied population. All statistical analyses were performed with the STATA v. 12 statistical software package (StataCorp LLC, College Station, Texas). Statistical significance was established at a $P<.05$.

\section{Results}

A total of 457 subjects were recruited, but 16 were excluded (3 smokers, 7 high-performance athletes, and 6 individuals were obese). Hence, 441 Mexico City residents without pulmonary disease were included. The subjects were ages 9-81 y, with a mean age of $38 \pm 18 \mathrm{y}$, median age of 32 (interquartile range, 9.2-81) y, $45 \%$ male $(n=199)$, and non-obese (BMI, $\left.25.05 \pm 4.21 \mathrm{~kg} / \mathrm{m}^{2}\right)$. The baseline data of the study population by sex, with expected differences between males and females in lung function, are shown in Table 1. The participants had $\mathrm{FEV}_{1}, \mathrm{FVC}$, and $\mathrm{FEV}_{1} / \mathrm{FVC}$ within normal range, and the percent of predicted was similar in both females and males. The potential participants who responded to an invitation to participate in the study were predominantly young adults, with only a smaller proportion of elderly men and women.

As demonstrated in Figure 1, VC and IC increased during growth up to adolescence in both males and females but then there was a slow, progressive decrease from age $30 \mathrm{y}$ onward. We found a significant difference in average \pm SD annual IC decline between females and males after age $30 \mathrm{y}$ : in males, this was $11 \pm 5.4 \mathrm{~mL}$, whereas, in females, this was $20.8 \pm 2.9 \mathrm{~mL}(P=.046)$. For VC, a significant 

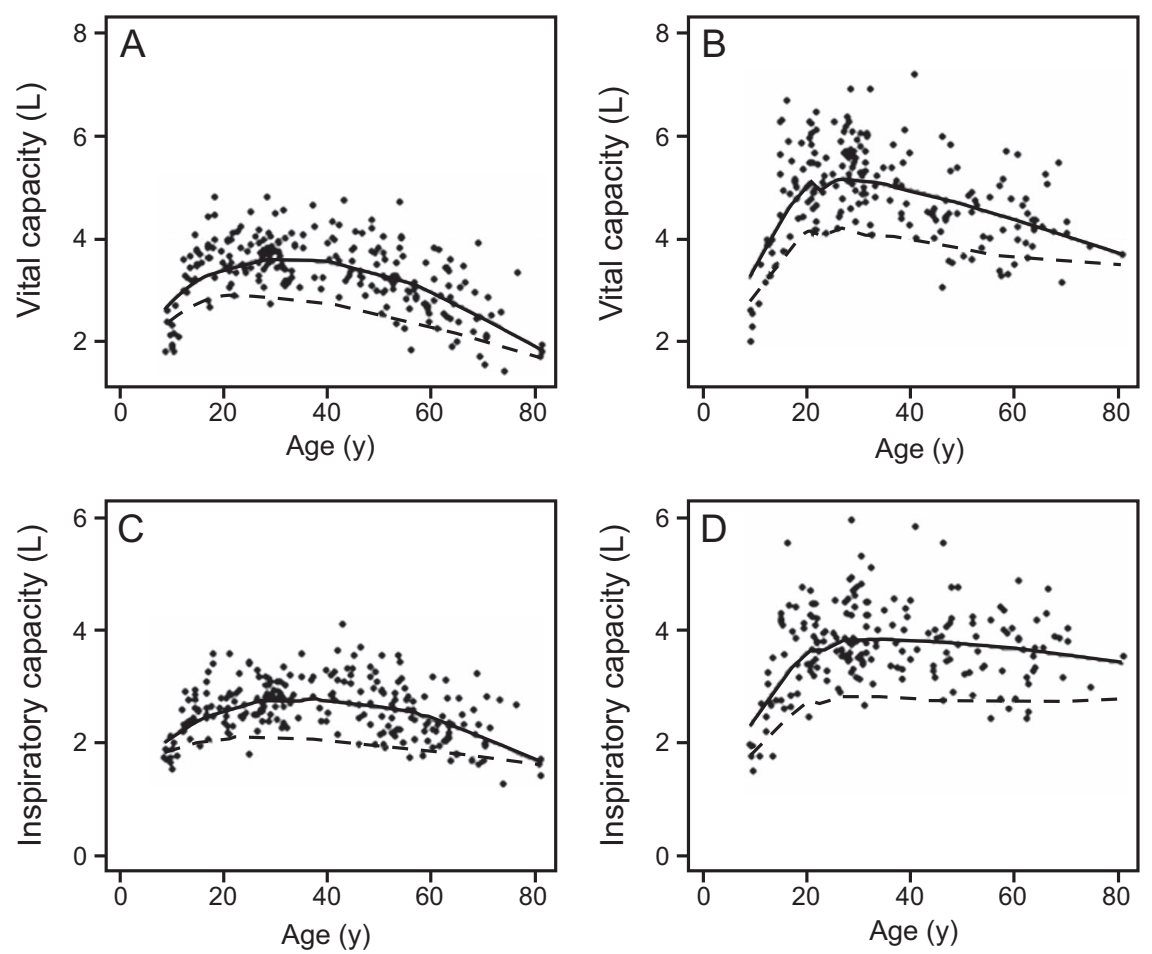

Fig. 1. Distribution of measured vital capacity and inspiratory capacity according to age for both sexes (men $[A$ and $C]$ and women $[B$ and $D]$ ). Solid lines show the median (50th percentile) of the prediction values, and the dotted line represents the lower limit of normality (5th percentile).

Table 2. Correlation Coefficients for IC and Slow VC

\begin{tabular}{|c|c|c|c|c|}
\hline \multirow{2}{*}{ Independent Variable } & \multicolumn{2}{|c|}{ IC } & \multicolumn{2}{|c|}{$\mathrm{VC}$} \\
\hline & $r$ & $P$ & $r$ & $P$ \\
\hline Age, y & -0.02 & .71 & -0.19 & $<.001$ \\
\hline Height, cm & 0.75 & $<.001$ & 0.83 & $<.001$ \\
\hline Weight, kg & 0.64 & $<.001$ & 0.54 & $<.001$ \\
\hline BMI, $\mathrm{kg} / \mathrm{m}^{2}$ & 0.23 & $<.001$ & 0.02 & .65 \\
\hline $\mathrm{BSA}, \mathrm{m}^{2}$ & 0.70 & $<.001$ & 0.63 & $<.001$ \\
\hline
\end{tabular}

Variables that exhibited a significant association with IC and VC were included in the multivariate model.

$\mathrm{IC}=$ inspiratory capacity

$\mathrm{VC}=$ vital capacity

$r=$ Pearson regression coefficient

$\mathrm{BMI}=$ body mass index

$\mathrm{BSA}=$ body surface area

decline after age $30 \mathrm{y}$ in females was $31 \pm 3.4 \mathrm{~mL}$, and $27 \pm$ $9.9 \mathrm{~mL}$ (mean $\pm \mathrm{SD}$ ) for males after age $40 \mathrm{y}$.

In the univariate analysis (Table 2), height, weight, BMI and BSA proved to be significantly associated with IC; whereas age, height, weight, body surface area were significantly associated with VC. We tested interaction terms between sex and age $^{2}$, but the inclusion of these terms did not add to the model, and the coefficients did not reach statistical significance. The models proposed in our study, as in previous studies (Table 3), 3,17-23 included as predicting variables, age, weight, height, BMI, and their squared terms, and were selected with the objective of optimizing $\mathrm{R}^{2}$ but also the Akaike information criterion and Bayesian information criterion. Best equations are shown in Tables 4 and 5, with an $\mathrm{R}^{2}$ for IC of $0.42-0.44$ and for VC, of 0.61-0.63. Residuals of the proposed equations had a random distribution as required by multiple regression models.

Measured IC and VC expressed as percentage of predicted by previously published reference equations are presented in Table 3. Measured IC and VC expressed as percentage of predicted by our equation were mean $\pm \mathrm{SD}$ $99.9 \pm 12 \%$ and $99.9 \pm 15 \%$, respectively. On average, our study population had IC significantly $>100 \%$ of predicted for all compiled reference equations, except for values published by Tantucci et al ${ }^{3}$ (including as a predictor BMI, $P=.14$ ). Measured VC, expressed as a percent of predicted, was significantly $>100 \% p$ when using Cordero et $\mathrm{al}^{23}$ and Caussade et $\mathrm{al}^{22}$ reference values but significantly $<100 \%$ when using Roca et al ${ }^{17}$ (which included BMI) (Figs. 2-5).

\section{Discussion}

This cross-sectional study described the changes in IC and slow VC in residents of Mexico City who lived 2,240 m above sea level from childhood to old age. It, therefore, spanned such important stages as the growth, plateau, and 


\section{Inspiratory Capacity and Vital Capacity at Moderate-High Altitude}

Table 3. Number of Subjects Included in Different Studies of IC (upper lines) and VC (lower lines), and Results of the Study Participants Expressed as Percentage of Predicted

\begin{tabular}{|c|c|c|c|c|c|c|}
\hline \multicolumn{2}{|c|}{ Reference Equation } & \multirow[t]{2}{*}{$N$} & \multirow[t]{2}{*}{$\begin{array}{c}\text { Study Subjects Compared } \\
\text { With Each Equation }\end{array}$} & \multirow[t]{2}{*}{$\begin{array}{l}\text { Measured Values, } \\
\text { Mean } \pm \text { SD }(\% \mathrm{p})^{*}\end{array}$} & \multirow[t]{2}{*}{$\begin{array}{c}\text { Difference } \\
\Delta \% \mathrm{p}^{\dagger}\end{array}$} & \multirow[t]{2}{*}{$P \ddagger$} \\
\hline Study & IC or $\mathrm{VC}$ & & & & & \\
\hline Tantucci et $\mathrm{al}^{3}$ & IC & 241 & 33 & $114 \pm 1.9$ & -10 & .012 \\
\hline Tantucci et $\mathrm{al}^{3}$ & with BMI, IC & 241 & 33 & $110 \pm 1.9$ & -5 & .14 \\
\hline Lisboa et al ${ }^{19}$ & IC & 155 & 125 & $111 \pm 0.7$ & -13 & $<.001$ \\
\hline Roca et al ${ }^{17}$ & IC & 340 & 387 & $109 \pm 0.3$ & -9 & $<.001$ \\
\hline Roca et al ${ }^{17}$ & with BMI, IC & 346 & 387 & $106 \pm 0.3$ & -6 & $<.001$ \\
\hline García Río et al ${ }^{20}$ & IC & 321 & 33 & $134 \pm 2.7$ & -30 & $<.001$ \\
\hline Neder et al ${ }^{18}$ & IC & 100 & 352 & $112 \pm 0.5$ & -12 & $<.001$ \\
\hline Marsh et $\mathrm{al}^{21}$ & IC & 212 & 302 & $112 \pm 0.5$ & -11 & $<.001$ \\
\hline Caussade et al 22 & IC & 245 & 66 & $115 \pm 0.7$ & -18 & $<.001$ \\
\hline Roca et al ${ }^{17}$ & $\mathrm{VC}$ & 340 & 388 & $98 \pm 0.2$ & 2 & $<.001$ \\
\hline Roca et al ${ }^{17}$ & with BMI, VC & 346 & 181 & $93 \pm 0.3$ & 8 & $<.001$ \\
\hline García Río et al ${ }^{20}$ & $\mathrm{VC}$ & 321 & 29 & $106 \pm 1.7$ & -5 & .24 \\
\hline Marsh et $\mathrm{al}^{21}$ & $\mathrm{VC}$ & 212 & 302 & $98 \pm 0.3$ & 2 & $<.001$ \\
\hline Cordero et $\mathrm{al}^{23}$ & $\mathrm{VC}$ & 591 & 369 & $105 \pm 0.3$ & -4 & $<.001$ \\
\hline Caussade et $\mathrm{al}^{22}$ & $\mathrm{VC}$ & 245 & 64 & $105 \pm 0.7$ & -8 & $<.001$ \\
\hline \multicolumn{7}{|c|}{$\begin{array}{l}\text { * The IC and VC of the studied population expressed as percentages of predicted by the different reference studies; if significantly }>100 \% \text { implies higher IC or VC than reference populations. } \\
\dagger \text { Difference \%p represents the measured values expressed as } \% \mathrm{P} \text { by our equation minus } \% \mathrm{P} \text { by described equations; a negative number means our subjects had higher IC or VC than the reference equation. } \\
\ddagger \text { Obtained by a paired } t \text { test compared predicted values from our equation vs predicted values from each reference equation. } \\
\text { IC }=\text { inspiratory capacity } \\
\text { VC = vital capacity } \\
\text { BMI = body mass index }\end{array}$} \\
\hline
\end{tabular}

Table 4. Best Predicting Equations From This Study for VC

\begin{tabular}{|c|c|c|c|c|c|c|c|}
\hline Variable & Constant & $\begin{array}{l}\text { Age } \\
\text { (y) }\end{array}$ & $\begin{array}{c}\mathrm{Age}^{2} \\
\left(\mathrm{y}^{2}\right)\end{array}$ & $\begin{array}{l}\text { Height } \\
(\mathrm{cm})\end{array}$ & $\mathrm{R}^{2}$ & $\begin{array}{l}\text { Root } \\
\text { MSE }\end{array}$ & $P$ \\
\hline \multicolumn{8}{|l|}{ Female } \\
\hline Median VC & -4.19 & 0.042 & -0.0006 & 0.045 & 0.63 & 0.41 & $<.001$ \\
\hline LLN VC & -4.58 & 0.052 & -0.0008 & 0.043 & $0.52 *$ & & \\
\hline \multicolumn{8}{|l|}{ Male } \\
\hline Median VC & -6.81 & 0.033 & -0.0005 & 0.067 & 0.61 & 0.58 & $<.001$ \\
\hline LLN VC & -6.27 & 0.046 & -0.0008 & 0.058 & $0.49^{*}$ & & \\
\hline \multicolumn{8}{|c|}{$\begin{array}{l}\text { Best models for the studied population and predicting equations recommended for our } \\
\text { population. } \\
\text { * pseudo } \mathrm{R}^{2} \text {. } \\
\text { VC = vital capacity } \\
\text { MSE = mean square error (the SD of the residuals) } \\
\text { LLN = lower limit of normal }\end{array}$} \\
\hline
\end{tabular}

aging of lung function by using current equipment and procedures. The main predictors of IC and VC were sex, age, and height, but, in general, the IC measured was higher than that predicted by other studies,, $317-23$ after adjusting for sex, height, age, and weight. In our analysis, we found a coefficient of variation for IC of mean \pm SD $3 \pm 2 \%$; in other study, this has been found to be mean \pm SD $5 \pm 3 \%^{1}$ The study population was predominantly Mexican mestizo with an important contribution of Amerindian genes, in a country where $32 \%$ of the total population resides at $>2,000 \mathrm{~m}$ above sea level. ${ }^{12}$ Previously, work by our group found that spirometry values obtained from a Mexican
Table 5. Best Predicting Equations From This Study for IC

\begin{tabular}{lllllllll}
\hline \hline \multicolumn{1}{c}{ Variable } & Constant & $\begin{array}{c}\text { Age } \\
(\mathrm{y})\end{array}$ & $\begin{array}{c}\mathrm{Age}^{2} \\
\left(\mathrm{y}^{2}\right)\end{array}$ & $\begin{array}{c}\text { Height } \\
(\mathrm{cm})\end{array}$ & $\mathrm{R}^{2}$ & $\begin{array}{c}\text { Root } \\
\text { MSE }\end{array}$ & $P$ \\
\hline Female & & & & & & & \\
$\quad$ Median IC & -2.01 & 0.0423 & -0.00055 & 0.025 & 0.44 & 0.37 & $<.001$ \\
LLN IC & -1.42 & 0.0304 & -0.00043 & 0.019 & $0.36^{*}$ & & \\
Male \\
$\quad$
\end{tabular}

population, adjusted by sex, height, and age, were higher than for other population groups. ${ }^{13}$ This may be due to a greater upper-body-segment to lower-body-segment ratio, which implied a larger thorax for height.

Although the explanation for these findings is currently unknown, residing at moderate altitude with chronic hypoxia may be a participating factor, ${ }^{25-27}$ together with genetic contributions due primarily to the higher proportion of Amerindian genes. ${ }^{27}$ Another possibility could be a relative increase in chest dimensions compared with height, as described for undernourished and underserved groups with short stature (stunting), which leads to shorter ex- 
tremities. ${ }^{28}$ Another study demonstrated that VC and alveolar capillary surface increased in natives at high altitude compared with sea-level populations. ${ }^{29}$ It is widely accepted that several factors may lead to large lungs in these individuals, such as the life-long exposure to hypoxia and genetic factors. The pattern of growth in body size and lung volume at high altitude is different from that observed at sea level and includes a larger lung volume and chest dimensions, particularly a larger residual volume ${ }^{14}$; also, infants and toddlers born and residing at high altitudes had higher functional residual capacity compared with subjects at sea level, likely secondary to an increase in alveolar number. ${ }^{28}$

Our study found that IC and VC increased similarly in girls and boys during growth and development before reach-

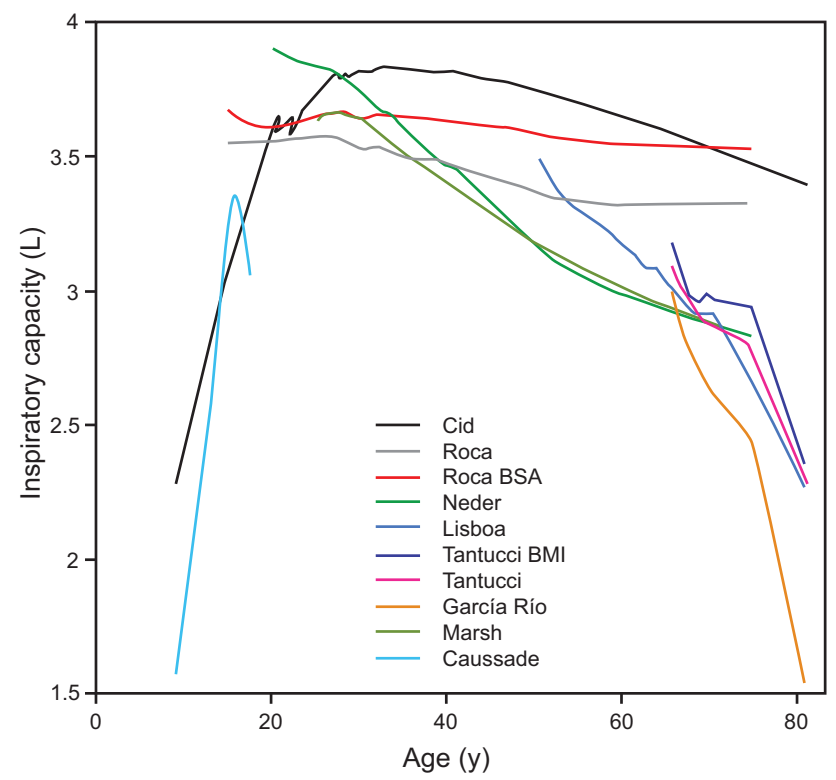

Fig. 2. Comparison of the regression line for measurements of inspiratory capacity in men with those previously published for other populations. ${ }^{3,17-23} \mathrm{BSA}=$ body surface area; $\mathrm{BMI}=$ body mass index. ing a short plateau, followed by a slow decline after age $30 \mathrm{y}$. This concurred with the phase of pulmonary growth and maturation in the first 2 decades of life, when this process accelerates to obtain its maximal function at approximately age $20 \mathrm{y}$ in women and age $25 \mathrm{y}$ in men. The annual IC drop after age $30 \mathrm{y}$ was, on average, $10 \mathrm{~mL}$ in men and $20 \mathrm{~mL}$ in women $(P=.046)$. The annual drop in $\mathrm{VC}$ after age $30 \mathrm{y}$ in females was $31 \mathrm{~mL}(P<.001)$, but, for men, a significant $\mathrm{VC}$ decline occurred only after age $40 \mathrm{y}$, and averaged $27 \mathrm{~mL} / \mathrm{y}(P<.001)$. The observed IC drop per year was less than that reported for $\mathrm{FEV}_{1}$ and IC in another study. ${ }^{11}$ At present, we do not know whether this decline in women was due to menopause or whether it was associated with lower pulmonary function, perhaps due to the effect of sex hormones on lung growth, muscle strength and function, and smooth-muscle relaxation in the airway. ${ }^{30}$ There also are reports that women experience a more-rapid increase in the kyphosis angle after age $40 \mathrm{y}$, which reaches its highest value after age $55 \mathrm{y} .{ }^{31}$

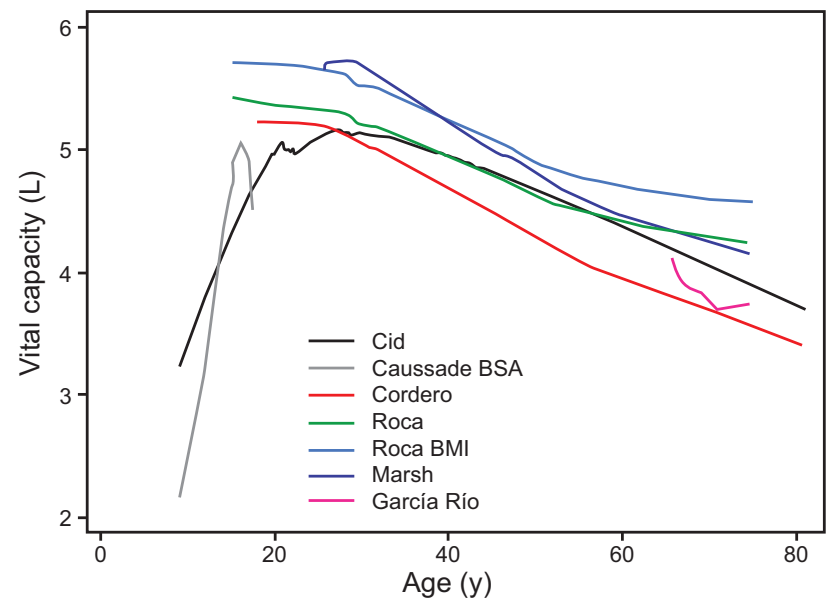

Fig. 4. Comparison of the regression line for measurements of vital capacity in men with those previously published for other populations. ${ }^{3,17-23} \mathrm{BSA}=$ body surface area; $\mathrm{BMI}=$ body mass index.

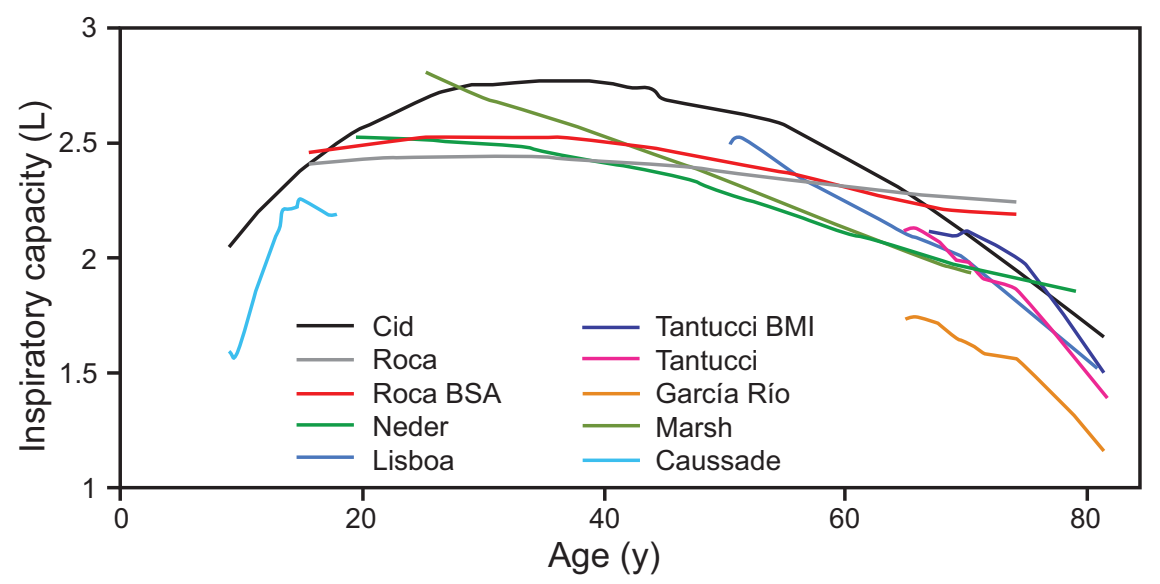

Fig. 3. Comparison of the regression line for measurements of inspiratory capacity in women with those previously published for other populations. ${ }^{3,17-23} \mathrm{BSA}=$ body surface area; BMI = body mass index. 


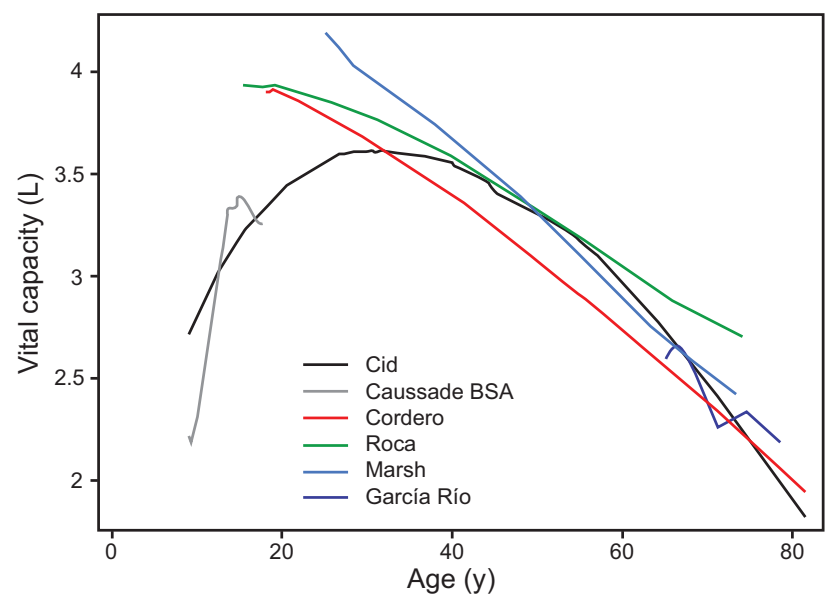

Fig. 5. Comparison of the regression line for measurements of vital capacity in women with those previously published for other populations. ${ }^{3,17-23} \mathrm{BSA}=$ body surface area; $\mathrm{BMI}=$ body mass index.

The decline of IC with aging can be explained by reduced lung elastic recoil, greater thoracic rigidity, and lower muscular strength. ${ }^{31,32}$ An increase in air trapping as large as $50 \%$ between ages 20 and $70 \mathrm{y}$, accompanied by decreases in VC to $\sim 75 \%$ of best values, was previously described. ${ }^{32}$ In contrast, total lung capacity does not seem to be modified by aging. ${ }^{33,34}$ It should be noted that the change in IC with age was not considered relevant in some of the equations previously described in Roca et al ${ }^{17}$ and Quanjer et al). ${ }^{11}$

Obtaining IC by spirometry is simpler than by plethysmography. Also, this procedure can identify hyperinflation at rest, in patients who experience postural changes, and during exercise. ${ }^{3,35} \mathrm{IC}$ at rest is described as an independent risk factor in exacerbation of COPD and mortality by any cause. ${ }^{4,6,36}$ Studies of subjects with COPD documented that air trapping develops as this condition progresses and results in decreased IC. ${ }^{37-39}$ Similarly, Pellegrino et als ${ }^{5}$ demonstrated that an increase in IC after bronchodilator use entails a reduction in dynamic hyperinflation that, in turn, improves exercise capacity and reduces dyspnea. ${ }^{5} \mathrm{Up}$ to $60 \%$ of patients with pulmonary hypertension present abnormalities in IC both at rest and during exercise, and individuals with decreased IC have a greater risk of mortality by any cause. ${ }^{40}$

In healthy individuals and in patients with mild obstruction, the difference between VC and FVC is practically zero; however, this difference increases in the presence of greater airway obstruction. ${ }^{8,9} \mathrm{FEV}_{1} / \mathrm{VC}$ detected the presence of airway obstruction in more individuals than did FEV $_{1} /$ FVC. $^{8}$ For example, the prevalence of COPD in the Swedish study increased from $14 \%$ to $16.8 \%$ when VC was used instead of only FVC, and this was independent of whether the $\mathrm{FEV}_{1} / \mathrm{FVC}<0.7$ or the lower limit of normal definition of COPD was applied. ${ }^{41}$ Finding that VC is higher than FVC indicated small-airway collapse and air trapping, and it may further indicate that static pulmonary hyperinflation is present. ${ }^{9}$

Our study had limitations. First, IC was measured only by slow spirometry; therefore, we were not able to determine the behavior of residual volumen (RV) or total lung capacity in our participants. However, total lung capacity was not observed to change with age in previous studies, ${ }^{33,34}$ and spirometric measurements of IC were shown to have a small coefficient of variation (for $\mathrm{VC}=0.035$ ) in most participants when studied with current equipment and methods. Previously, predicted IC was measured nearly exclusively by plethysmography or by the inert gas method, but the inert gas method rendered it more difficult to obtain simple reliable measurements. In contrast, spirometric IC and VC measurements can be performed easily and accurately in different settings. Second, this was a crosssectional study, which implies that many birth cohorts were included in our study and results often differed from those obtained from longitudinal equations. ${ }^{42}$ Third, our population was not obtained by a sampling method representative of the population; however, the participants were more numerous than in previous studies and included a wide age range, which represented a considerable advantage.

\section{Conclusions}

The IC in our sample of healthy individuals who lived 2,240 $\mathrm{m}$ above sea level was higher than that reported in previous $\mathrm{FEV}_{1} / \mathrm{FVC}<0.7$ studies for European and Latin-American subjects of similar height, sex, and age at sea level. Our study provided a robust IC and VC reference equation for persons who lived at a moderate altitude from childhood to old age.

\section{REFERENCES}

1. Wanger J, Clausen JL, Coates A, Pedersen OF, Brusasco V, Burgos $\mathrm{F}$, et al. Standardisation of the measurement of lung volumes. Eur Respir J 2005;26(3):511-22.

2. Stocks J, Quanjer PH. ATS Workshop on Lung Volume Measurements. Official Statement of The European Respiratory Society. Reference values for residual volume, functional residual capacity and total lung capacity Eur Respir J 1995;8(3):492-506.

3. Tantucci C, Pinelli V, Cossi S, Guerini M, Donato F, Grassi V; SARA Study Group. Reference values and repeatability of inspiratory capacity for men and women aged 65-85. Respir Med 2006; 100(5):871-877.

4. Casanova C, Cote C, de Torres JP, Aguirre-Jaime A, Marin JM, Pinto-Plata $\mathrm{V}$, et al. Inspiratory to total lung capacity ratio predicts mortality in patients with chronic obstructive pulmonary disease. Am J Respir Crit Care Med 2005;171(6):591-597.

5. Pellegrino R, Viegi G, Brusasco V, Crapo RO, Burgos F, Casaburi $\mathrm{R}$, et al. Interpretative strategies for lung function tests. Eur Respir J 2005;26(5):948-968. 
6. Tantucci C, Donati P, Nicosia F, Bertella E, Redolfi S, De Vecchi M, et al. Inspiratory capacity predicts mortality in patients with chronic obstructive pulmonary disease. Respir Med 2008;102(4):613-619.

7. Miller MR, Hankinson J, Brusasco V, Burgos F, Casaburi R, Coates A, et al; ATS/ERS Task Force. Standardisation of spirometry. Eur Respir J 2005;26(2):319-338.

8. Barros AR, Pires MB, Raposo NM. Importance of slow vital capacity in the detection of airway obstruction. J Bras Pneumol 2013; 39(3):317-322.

9. Yuan W, He X, Xu QF, Wang H-Y, Casaburi R. Increased difference between slow and forced vital capacity is associated with reduced exercise tolerance in COPD patients. BMC Pulm Med 2014;14:16.

10. Enright PL, Kronmal RA, Higgins M, Schenker M, Haponik EF. Spirometry reference values for women and men 65 to 85 years of age. Cardiovascular health study. Am Rev Respir Dis 1993;147(1):125-133.

11. Quanjer PH, Andersen LH, Tammeling GJ. Static Lung Volumes And Capacities. Clin Respir Physiology 1983;19:11-21.

12. Pérez-Padilla R. Population distribution residing at different altitudes: implications for hypoxemia. Arch Med Res 2002;33(2):162-166.

13. Pérez-Padilla JR, Regalado-Pineda J, Vázquez-García JC. Reproducibility of spirometry in Mexican workers and international reference values. Salud Publica Mex 2001;43(2):113-121.

14. Frisancho AR. Developmental functional adaptation to high altitude: review. Am J Hum Biol 2013;25(2):151-168.

15. Williams JH Jr, Bencowitz HZ. Differences in plethysmographic lung volumes. Effects of linked vs unlinked spirometry. Chest 1989; 95(1):117-123.

16. Hankinson JL, Odencrantz JR, Fedan KB. Spirometric reference values from a sample of the general U.S. population. Am J Respir Crit Care Med 1999;159(1):179-187.

17. Roca J, Burgos F, Barberà JA, Sunyer J, Rodriguez-Roisin R, Castellsagué $\mathrm{J}$, et al. Prediction equations for plethysmographic lung volumes. Respir Med 1998;92(3):454-460.

18. Neder JA, Andreoni S, Castelo-Filho A, Nery LE. Reference values for lung function tests. I. Static volumes. Braz J Med Biol Res 1999;32(6):703-717.

19. Lisboa C, Leiva A, Pinochet R, Repetto P, Borzone G, Díaz O. Reference values for inspiratory capacity in healthy nonsmokers over age 50 years. Arch Bronconeumol 2007;43(9):485-489.

20. Garcia-Rio F, Dorgham A, Pino JM, Villasante C, Garcia-Quero C, Alvarez-Sala R. Lung volume reference values for women and men 65 to 85 years of age. Am J Respir Crit Care Med 2009;180(11): 1083-1091.

21. Marsh S, Aldington S, Williams M, Weatherall M, Shirtcliffe P, McNaughton A, et al. Complete reference ranges for pulmonary function tests from a single New Zealand population. N Z Med J 2006;119(1244):U2281.

22. Caussade S, Pulgar D, Vega-Briceno L, Viviani P, Diaz C, Contreras I, Sanchez I. Plethysmographic lung volumes in normal Chilean children and adolescents. Pediatr Pulmonol 2008;43(9):866-873.

23. Cordero PJ, Morales P, Benlloch E, Miravet L, Cebrian J. Static lung volumes: reference values from a Latin population of Spanish descent. Respiration 1999;66(3):242-250.

24. Quanjer PH, Stanojevic S, Cole TJ, Baur X, Hall GL, Culver BH, et al; ERS Global Lung Function Initiative. Multi-ethnic reference val- ues for spirometry for the 3-95-yr age range: the global lung function 2012 equations. Eur Respir J 2012;40(6):1324-1343.

25. Schoene RB. Limits of human lung function at high altitude. J Exp Biol 2001;204(Pt 18):3121-3127.

26. Cogo A. The lung at high altitude. Multidiscip Respir Med 2011; 6(1):14-15.

27. Kiyamu M, Bigham A, Parra E, León-Velarde F, Rivera-Chira M, Brutsaert TD. Developmental and genetic components explain enhanced pulmonary volumes of female peruvian quechua. Am J Phys Anthropol 2012;148(4):534-542.

28. Llapur CJ, Martínez MR, Caram MM, Bonilla F, Cabana C, Yu Z, Tepper RS. Increased lung volume in infants and toddlers at high compared to low altitude. Pediatr Pulmonol 2013;48(12):1224-1230.

29. Brody JS, Lahiri S, Simpser M, Motoyama EK, Velasquez T. Lung elasticity and airway dynamics in Peruvian natives to high altitude. J Appl Physiol 1977;42(2):245-251.

30. Pata O, Atiş S, Utku Oz A, Yazici G, Tok E, Pata C, et al. The effects of hormone replacement therapy type on pulmonary functions in postmenopausal women. Maturitas 2003;46(3):213-218.

31. Lowery EM, Brubaker AL, Kuhlmann E, Kovacs EJ. The aging lung. Clin Interv Aging 2013;8:1489-1496.

32. Janssens JP, Pache JC, Nicod LP. Physiological changes in respiratory function associated with ageing. Eur Respir J 1999; 13(1):197-205.

33. Lum S, Stocks J, Stanojevic S, Wade A, Robinson P, Gustafsson P, et al. Age and height dependence of lung clearance index and functional residual capacity. Eur Respir J 2013;41(6):1371-1377.

34. Verbanck S, Thompson BR, Schuermans D, Kalsi H, Biddiscombe M, Stuart-Andrews C, et al. Ventilation heterogeneity in the acinar and conductive zones of the normal ageing lung. Thorax 2012;67(9): 789-795.

35. O'Donnell DE, Guenette JA, Maltais F, Webb KA. Decline of resting inspiratory capacity in COPD: the impact on breathing pattern, dyspnea, and ventilatory capacity during exercise. Chest 2012;141(3):753-762.

36. Guenette JA, Chin RC, Cory JM, Webb KA, O'Donnell DE. Inspiratory Capacity during Exercise: Measurement, Analysis, and Interpretation. Pulm Med 2013;2013:95608.

37. Celli BR, Decramer M, Lystig T, Kesten S, Tashkin DP. Longitudinal inspiratory capacity changes in chronic obstructive pulmonary disease. Respir Res 2012;13:66.

38. Trigo MJM, Sánchez-Barón. Valoración funcional del paciente con EPOC [Functional assessment of the patient with COPD]. Arch Bronconeumol 2005;41:18-23.

39. Di Marco F, Milic-Emili J, Boveri B, Carlucci P, Santus P, Casanova $\mathrm{F}$, et al. Effect of inhaled bronchodilators on inspiratory capacity and dyspnea at rest in COPD. Eur Respir J 2003;21(1):86-94.

40. Richter MJ, Tiede H, Morty RE, Voswinckel R, Seeger W, Schulz R, et al. The prognostic significance of inspiratory capacity in pulmonary arterial hypertension. Respiration 2014;88(1):24-30.

41. Torén K, Olin AC, Lindberg A, Vikgren J, Schiöler L, Brandberg J, et al. Vital capacity and COPD: the Swedish CArdioPulmonary bioImage Study (SCAPIS). Int J Chron Obstruct Pulmon Dis 2016;11:927-933.

42. Martínez-Briseño D, Fernández-Plata R, Gochicoa-Rangel L, TorreBouscoulet L, Rojas-Martínez R, Mendoza L, et al. Longitudinal lung function growth of Mexican children compared with international studies. PLoS One 2013;8(10):e77403.

This article is approved for Continuing Respiratory Care Education credit. For information and to obtain your CRCE

(free to AARC members) visit www.rcjournal.com

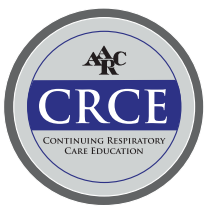

